\title{
Erratum to: Effect of mold type, diameter, and uncured composite removal method on depth of cure
}

\author{
Frederick A. Rueggeberg ${ }^{1} \cdot$ Richard B. Price ${ }^{2} \cdot$ Jessie Harlow $^{2} \cdot$ Braden Sullivan $^{2}$
}

Published online: 28 January 2016

(C) Springer-Verlag Berlin Heidelberg 2016

Erratum to: Clinical Oral Investigations

DOI 10.1007/s00784-015-1672-4

The ePub version of this article published on December 2, 2015 contained a typesetting error in the order of the authors' names and affiliations. The correct order and affiliations are reported below.

The online version of the original article can be found under doi:10.1007/ s00784-015-1672-4.

$\triangle$ Richard B. Price

rbprice@dal.ca

1 Department of Oral Rehabilitation, College of Dental Medicine, Georgia Regents University, Augusta, GA, USA

2 Department of Dental Clinical Sciences, Faculty of Dentistry,

Dalhousie University, Halifax, NS, Canada 